\title{
Three-Year Survival after Transcatheter Aortic Valve Replacement: Findings from the Marshfield Aortic Valve Experience (MAVE) Study
}

Peter E. Umukoro, MD, MPH, ScD; Paul Yeung-Lai-Wah, MD; Sunil Pathak, MD; Sabri Elkhidir, MD; Deepa Soodi, MD; Brooke Delgoffe, MS; Richard Berg, MS; Kelley P. Anderson, MD; and Romel J. Garcia-Montilla, MD, MEd, PhD, MSc

Background: Transcatheter aortic valve replacement (TAVR) is a rapidly evolving treatment for severe aortic stenosis. However, uncertainties exist for optimal valve selection as there are few long-term studies comparing patient survival by valve type.

Objective: We hypothesized that self-expandable valves (SEV) would provide a survival advantage over balloon expandable valves (BEV), as SEV continue to expand and might better accommodate to the anatomy of the aortic valve over time.

Methods: We examined outcomes according to valve type from a rural tertiary referral center between 2012 and 2017.

Results: Out of 269 patients, 77 deaths (28.6\%) occurred over the study period with 6 deaths by I month post-TAVR and 37 deaths by I year post-TAVR. The median observation time for survivors was 21.5 months. The probability of survival at 3 years was $60.7 \%$ and $61.9 \%$ for patients who underwent treatment with SEV and BEV, respectively. There was no statistically significant difference in overall patient survival with or without adjustment for factors such as age, sex, race, and aortic valve area.Additionally, in a secondary analysis restricted to those patients treated in later years (2015-20I7) survival among patients with $B E V$ appeared superior $(H R=0.456, P=0.015)$.

Conclusion: Patients who underwent TAVR at a rural medical center with SEV showed similar survival compared to those who received a BEV. Superior survival was observed among those who received BEV versus SEV between 2015 and 2017

Keywords: TAVR; Mortality; Aortic stenosis

$\mathrm{S}$ evere symptomatic aortic stenosis was previously a grave diagnosis especially in those for whom open heart surgery poses high and prohibitive risk. ${ }^{1,2}$ Transcatheter aortic valve replacement (TAVR) has evolved over the last decade as a novel treatment for severe aortic stenosis, particularly in clinical scenarios where patients are too ill to have open heart surgery or have failed surgical bio-prosthesis. ${ }^{3,4}$ The application of TAVR is expanding to patients with aortic stenosis and intermediate and low surgical risk..$^{5-7}$

Different types of valves have been designed for use in the TAVR procedure. ${ }^{8,9}$ Self-expandable valves (SEV) are unique in that they are self-expanding; therefore, they can be
Corresponding Author: Peter E. Umukoro, MD, MPH, ScD, Indiana University, Department of Nephrology, 340 W 10th St. \#6200, Indianapolis, IN 46202, Email: peu258@mail.harvard.edu, Tel: (617) 874-6908, Fax: (3I7) 2748575
Received: November 22, 2019

Ist Revision: June 30, 2020

2nd Revision: August 25, 2020

Accepted: September 10, 2020 
recaptured and repositioned for accurate valve placement in the supra-annulus position above the aortic valve. ${ }^{2,10}$ Balloonexpandable valves (BEV), on the other hand, mimic the structure of the native aortic valve where it seats. Various iterations of the valve types described have been developed for TAVR, ${ }^{11}$ and clinical trial data demonstrate the effectiveness of both types of valves over a period of one year or less. ${ }^{12,13}$ There is a growing body of literature of longer-term data., ${ }^{9,13}$ However, beyond clinical trials, there are few observational studies that compare TAVR survival outcomes according to valve type in real-life settings for a period longer than 1 year.

Therefore, the purpose of our study was to evaluate the longterm survival of patients who received SEV and BEV for TAVR in community practice from 2012 to 2017 . We analyzed data from a tertiary referral setting in central Wisconsin, USA, and compared survival and mortality outcomes for SEV and BEV. We hypothesized that SEV would provide a survival advantage over BEV.

\section{Methods}

Study Population

This was a retrospective study that included all inoperable high risk and prohibitive risk patients for surgical aortic valve replacement (SAVR) that received TAVR in a single hospital between January 1, 2012, and December 31, 2017 since the inception of the TAVR program in our hospital. TAVR was being offered as the only medical option for inoperable high risk and prohibitive risk patients who were going palliative.

Prohibitive risk was defined as any one of Society of Thoracic Surgeons (STS) Predicted Risk of (postoperative) Mortality $\geq 8 \%$, severe calcification in the aorta such as porcelain aorta; severe frailty; hostile chest anatomy; severe liver disease (Model for End-stage Liver Disease score >12); severe pulmonary hypertension; or extenuating anatomy such as internal mammary grafts at risk of injury, increased bleeding diathesis, severe dementia, chemotherapy for malignancy, immobility, or acquired immunodeficiency syndrome. Operative risk was determined by the cardiac surgeon and the interventional cardiologist. Patients were deemed high risk or inoperable if the STS risk score was $>8 \%$, or the Heart Team considered the patient to be high risk or inoperable for clinical reasons. Patients were deemed intermediate risk either based on the assessment of the Heart Team or if the STS score was between $4 \%$ and $8 \%$.

Table 1. Demographics and characteristics of patient population for balloon expandable and self-expandable TAVR valves.

\begin{tabular}{|c|c|c|c|}
\hline Characteristic & $\begin{array}{l}\text { Balloon }(\mathrm{N}=183) \\
\text { Mean (SD) }\end{array}$ & $\begin{array}{c}\text { Self-Expanding }(\mathrm{N}=86) \\
\text { Mean (SD) }\end{array}$ & $P$ value \\
\hline Age & $83(6.5)$ & $81(9.0)$ & 0.130 \\
\hline$<70^{+}$ & $11(6.0 \%)$ & $5(5.8 \%)$ & \multirow{4}{*}{0.252} \\
\hline $70-79^{+}$ & $40(21.9 \%)$ & $28(32.6 \%)$ & \\
\hline $80-89^{+}$ & $115(62.8 \%)$ & $44(51.2 \%)$ & \\
\hline $90+^{+}$ & $17(9.3 \%)$ & $9(10.5 \%)$ & \\
\hline Male (\%) & $96(52.5 \%)$ & $38(44.2 \%)$ & 0.206 \\
\hline White (\%) & $179(97.8 \%)$ & 85 (98.8\%) & 0.562 \\
\hline BMI & $30.6(6.4)$ & $32.0(7.5)$ & 0.171 \\
\hline eGFR & $56.2(19.5)$ & $54.0(19.6)$ & 0.581 \\
\hline Hemoglobin & $12.5(1.5)$ & $12.0(1.6)$ & 0.722 \\
\hline $\mathrm{HbA1c}$ & $6.1(0.9)$ & $6.1(1.0)$ & 0.852 \\
\hline FEV1(\% predicted)* & $42.7(38.7)$ & $66.3(33.0)$ & 0.029 \\
\hline Heart Failure (\%) & $157(85.8 \%)$ & $76(88.4 \%)$ & 0.562 \\
\hline CAD (\%) & $161(88.0 \%)$ & $76(88.4 \%)$ & 0.926 \\
\hline \multicolumn{4}{|l|}{ NYHA Class } \\
\hline 1 & $2(1.2 \%)$ & $1(1.3 \%)$ & \multirow{4}{*}{0.739} \\
\hline 2 & $48(28.6 \%)$ & $17(21.8 \%)$ & \\
\hline 3 & $102(60.7 \%)$ & $52(66.7 \%)$ & \\
\hline 4 & $16(9.5 \%)$ & $8(10.3 \%)$ & \\
\hline COPD (\%) & 67 (36.6\%) & $23(26.7 \%)$ & 0.110 \\
\hline Stroke (\%) & 25 (13.7\%) & $6(7.0 \%)$ & 0.109 \\
\hline Diabetes (\%) & 90 (49.2\%) & 37 (43.0\%) & 0.345 \\
\hline
\end{tabular}

$\mathrm{SD}=$ standard deviation, \%=percentage, $\mathrm{BMI}=$ body mass index, eGFR=estimated glomerular filtration rate based on creatinine clearance, $\mathrm{HbA} 1 \mathrm{c}=$ glycated hemoglobin, $\mathrm{FEV} 1=$ forced expiratory volume in 1 second, $\mathrm{CAD}=$ coronary artery disease, COPD=chronic obstructive pulmonary disease

+Number and percentages (\%) reported instead of mean and standard deviation *FEV1 (\% predicted) reported for patients with COPD 


\section{Data Abstraction}

All patient data were extracted from the electronic health records of Marshfield Clinic Health System (MCHS) obtained by mapping with international classification of disease (ICD) versions 9 and 10 billing codes for TAVR. Data abstraction was done manually and electronically from June 2017 to February 2018. Baseline echocardiographic variables were abstracted manually by reviewing the echocardiography reports of patients whose echocardiograms were performed within one month of TAVR during their pre-operative evaluation. All other data were electronically abstracted. A proportion (10\%) of the electronically abstracted data was manually verified to validate the accuracy of the data abstraction and found that the data abstraction was done correctly $98.7 \%$ of the time; discrepancies were clarified by two independent reviewers.

\section{Variables}

Demographic, clinical, echocardiographic, and vital status data were collected (Table 1). Demographic data obtained included patient age, sex, and race. Clinical data included body mass index (BMI), renal function based on estimated glomerular filtration rate of creatinine clearance, diagnosis of diabetes and recent glycated hemoglobin level during the preoperative evaluation for TAVR, heart failure and New York Heart Association (NYHA) class, coronary artery disease, diagnosis of chronic obstructive pulmonary disease (COPD), percent forced expiratory volume in one second (FEV1) during pre-operative evaluation for TAVR, and history of stroke. Echocardiographic assessment was performed in accordance with Valve Academic Research Consortium (VARC) recommendations. ${ }^{15-23}$ Echocardiographic data were obtained from 2D and, when available, 3D transthoracic echocardiogram that included measures of aortic valve area, valve area per body surface area, left ventricular ejection fraction, mean aortic gradient, peak aortic gradient, dimensionless velocity index, maximum velocity across the aortic valve, and the acceleration time.

\section{Exposure}

Patients underwent TAVR and were followed up per standard of care procedures. TAVR valve selection was determined by two surgeons/cardiologists, and patients either received SEV or BEV. Surgeon's determination of valve type was based on three dimensional anatomy including size and convolution of the stenosed valve on imaging. The $86 \mathrm{SEVs}$ included the 38 Medtronic CoreValve, 27 CoreValve Evolut R, and 21 CoreValve PRO; while the 183 BEVs included the 135 Edwards Sapien 3 and 48 Edwards Sapien XT models. The primary study outcome was all-cause mortality. The primary study outcome was allcause mortality.

\section{Statistical Analyses}

Comparisons of continuous demographic and baseline variables by valve type were done using the Wilcoxon rank sum test, while chi-square tests were used with categorical variables. Multivariable models included variables that were chosen $a$ priori that were thought to be independently associated with mortality. These included age, sex, race, and aortic valve area. We summarized survival at the following time points of interest: 30 days, 1 year, 2 years, and 3 years post-TAVR using Kaplan Meier estimates. We fitted Cox proportional hazards survival models in our multivariate analyses and calculated $95 \%$ confidence intervals for hazard ratios of each of the variables in the models. Additionally, we performed a secondary analysis restricting our study period from 2015-2017, as there was no SEV TAVR prior to 2015. All $P$ values reported were two-sided, and a significant value of $<0.05$ was deemed statistically significant. All data analyses were conducted using SAS version 9.4 (SAS Institute, Cary, $\mathrm{NC}$, USA). Institutional Review Board approval was awarded prior to chart review in accordance with the Code of Ethics of the World Medical Association (Declaration of Helsinki).

\section{Results}

Patient Population and Baseline Characteristics

Baseline demographic and clinical characteristics of 269 patients who were deemed high and at prohibitive risk for SAVR are summarized in Table 1. Mean age of patients was comparable

Figure 1. Number of TAVRs by valve type and dates. 
Table 2. Echocardiographic pre-operative parameters by valve type of patient population.

\begin{tabular}{lccc}
\hline Parameters & $\begin{array}{c}\text { Balloon } \\
\text { Mean (SD) }\end{array}$ & $\begin{array}{c}\text { Self-Expanding } \\
\text { Mean (SD) }\end{array}$ & $\boldsymbol{P}$ value \\
\hline Aortic valve area & $0.78(0.21)$ & $0.84(0.22)$ & 0.028 \\
Valve area/BSA & $0.40(0.11)$ & $0.43(0.12)$ & 0.041 \\
LVEF (\%) & $56.3(12.9)$ & $57.1(14.2)$ & 0.396 \\
Mean gradient & $43.1(16.5)$ & $40.4(15.5)$ & 0.146 \\
Velocity Index & $0.24(0.09)$ & $0.25(0.06)$ & 0.047 \\
Aortic valve Vmax & $4.1(0.8)$ & $4.0(0.7)$ & 0.260 \\
Acceleration time & $108.7(28.8)$ & $110.2(23.3)$ & 0.818 \\
\hline
\end{tabular}

$\mathrm{BSA}=$ body surface area, LVEF=Left Ventricular Ejection Fraction, Vmax =maximum velocity

for both valve types ( 83 years and 81 years for BEV and SEV, respectively), though the age range for SEV was larger than BEV (29 - 94 years vs. 61 - 94 years). About $10 \%$ of patients were over 90 -years-of-age in both valve groups. Over four-fifths of patients had coronary artery disease and heart failure, with NYHA class 3 being the most common subgroup. There were no statistically significant differences in baseline demographics and other clinical characteristics of patients who received either valve type, nor were there differences in major comorbidities and cardiovascular risk factors between the valve groups. However, among patients with COPD, the percent of predicted FEV1 was significantly lower in patients who received BEV versus SEV ( $42.7 \%$ vs. $66 \%, P=0.029)$ (Table 1 ).

Comparison of baseline echocardiographic data revealed no significant differences in echocardiographic characteristics of the aortic valve and left ventricular function except for aortic valve area, which was statistically significantly smaller among patients who received the BEV (BEV $0.78 \mathrm{~cm}^{2}$ versus SEV 0.84 $\mathrm{cm}^{2}, P=0.028$ ) (Table 2).

Although the aortic valves were more stenosed at baseline among patients who received BEVs, larger TAVR sizes were used in patients who received SEV (Table 3). Over $90 \%$ of patients received their TAVR using the transfemoral approach, and there were no differences between valve groups (Table 4). More patients (183) received BEV TAVR compared with SEV TAVR (86) during the entire study period from 2012 to 2017, and most SEV were used for patients from 2015 to 2017 (Figure 1).

\section{Follow-up}

All patients were followed using the MCHS electronic medical record from the TAVR until death or their most recent contact with MCHS. All non-deceased patients had at least one follow-up visit within the MCHS; thus, we could determine their vital status at that time. We obtained death certificates for deceased patients when cause of death was not available within the MCHS medical records. The median (interquartile range) observation time for survivors was 21.5 months $(13.8,30.7)$. There were 200 patients that contributed at least one year observation time, and only 32 patients had less than one year observation time.

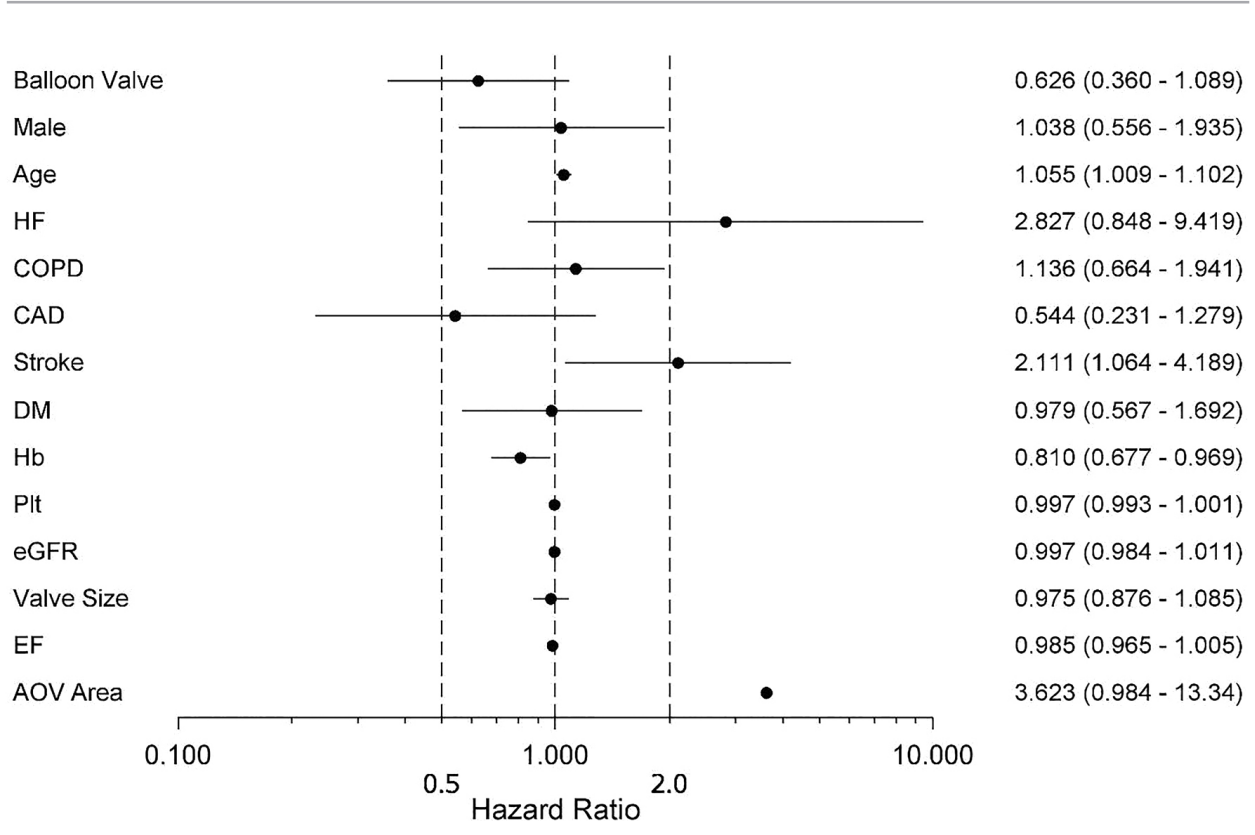

Figure 2. Forest plot of variables included for analysis in the final Kaplan-Meier survival model.
Outcome

Survival was similar in both valve groups, and at 3 years was estimated to be about $62 \%$ (95\% confidence interval: 50.3 , 71.7) for BEV and $60.7 \%(95 \%$ confidence interval: $44.9,73.2)$ for SEV (Table 5). There was no statistically significant difference in survival by valve group, even after adjustment for all covariates (Hazard ratio of 0.626 with $95 \%$ confidence interval of 0.36 to $1.09, P$ value 0.097) (Figures 2 and 3).

\section{Secondary Analyses}

As there were only a few patients who received SEV TAVR before 2015, we performed a secondary analysis to evaluate the time dependence of our results by restricting our 


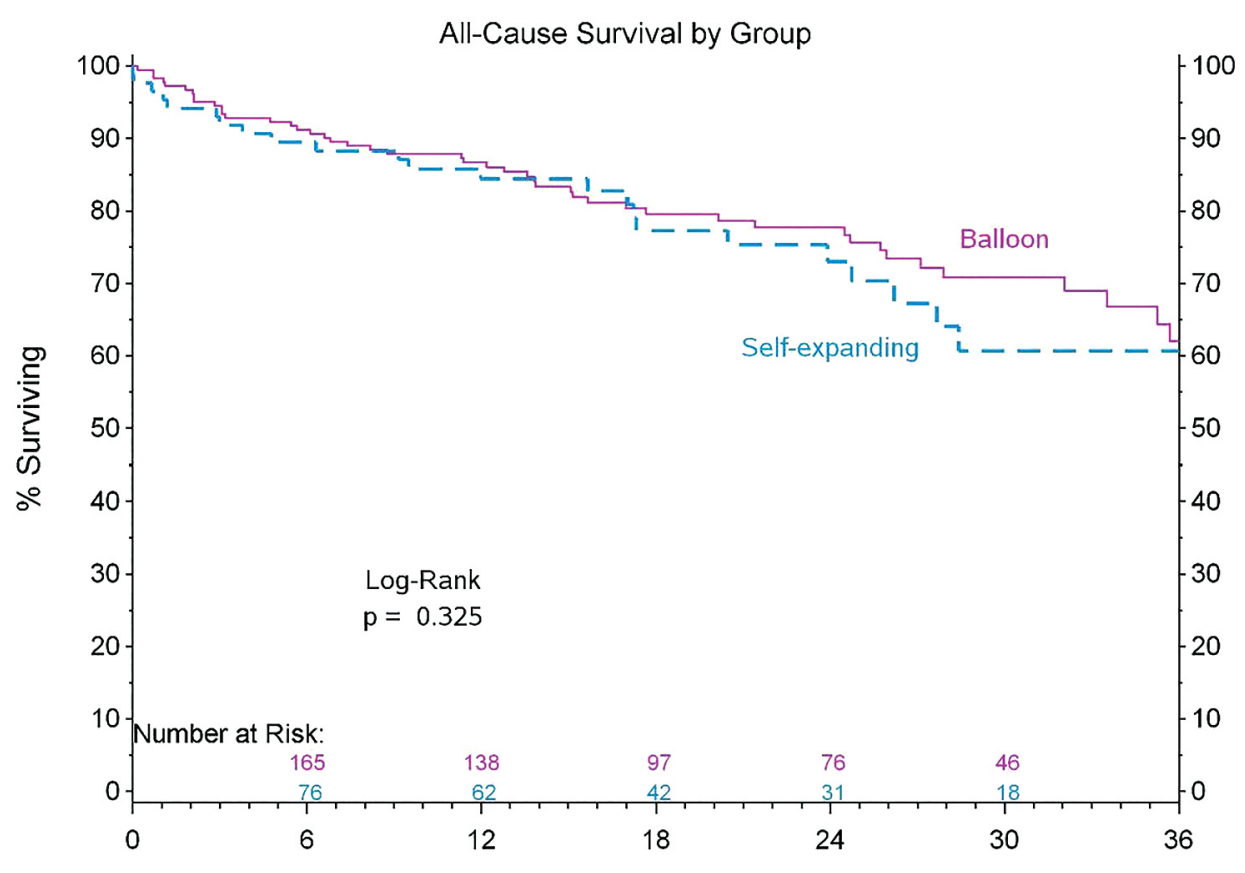

Figure 3. Kaplan-Meier survival curve for all 269 patients with TAVR from 2012 to 2017.

$33.7 \%$ and $22.3 \%$, respectively, translating to a survival of $66.3 \%$, which is greater than the $60.7 \%$ survival rate noted in our study. ${ }^{3}$ These results are similar to Deeb et $\mathrm{al}^{24}$ where post-operative outcomes of TAVR valves were compared to SAVR valves; the 3 -year all-cause mortality rate for TAVR valves was $32.9 \%$, with a corresponding survival rate of $67.1 \% .^{24}$

In a secondary outcome analyses of the PARTNER1 trial by Kapadia et $\mathrm{al}^{25}$ which was a randomized controlled trial to compare one year mortality of TAVR among inoperable aortic stenosis versus standard treatment, the 5-year mortality rate reported was $71.8 \%$, with a Kaplan-Meier survival estimate at 3 years of $60 \%-65 \%$, which is comparable to our study. Similar results were noted from a

samples to only TAVRs done between 2015 and 2017. With this restricted sample, there was a survival advantage of BEV compared to SEV (Hazard ratio of 0.456 with $95 \%$ confidence interval of 0.242 to $0.860, P$ value 0.015 ).

\section{Discussion}

Similar survival was noted in patients receiving BEV (61.9\%) and SEV (60.7\%) for up to 3 years at MCHS, though these results are dependent in part on the proportion of TAVR valves selected over time. Our 3-year survival rates were slightly lower but comparable to those found in a systematic review of 31 studies by Chakos et a $1^{14}$ whose 3 -year aggregate mortality was $65 \%$.

In the prospective nonrandomized ADVANCE study, Bleiziffer et $\mathrm{al}^{3}$ evaluated the mid-term performance of the self-expandable CoreValve and found that after 3 years of TAVR, all-cause mortality and cardiovascular mortality was

Table 3. TAVR valve size by valve type.

\begin{tabular}{lccccc}
\hline TAVR & \multicolumn{2}{c}{$\begin{array}{c}\text { Balloon } \\
\mathbf{N}=\mathbf{1 8 3})\end{array}$} & \multicolumn{2}{c}{$\begin{array}{c}\text { Self-Expanding } \\
\text { (N=86) }\end{array}$} \\
size & $\mathrm{N}$ & $\%$ & $\mathrm{~N}$ & $\%$ & P value \\
\hline 20 & 2 & 1.1 & 0 & 0 & \\
23 & 68 & 37.4 & 9 & 10.5 & \\
26 & 77 & 42.3 & 30 & 34.9 & $<0.001$ \\
29 & 35 & 19.2 & 32 & 37.2 & \\
31 & 0 & 0 & 7 & 8.1 & \\
34 & 0 & 0 & 8 & 9.3 & \\
\hline
\end{tabular}

registry-based study of TAVR outcomes in the United Kingdom, where a 3 -year survival rate of $61.2 \%$ was reported..$^{25}$

In a related study, Martin et $\mathrm{al}^{26}$ evaluated relative survival post-transcatheter aortic valve implantation compared to an age-matched population in England and Wales for patients $\leq 85$ years for up to 3 years and found that the mortality hazards by 1-year follow-up were not significantly different from those of the matched general population, and by 3 years, the relative survival of patients was comparable with the matched general population. ${ }^{26}$ They reported 1-year and 3-year survival rates of $90.2 \%$ and $83.8 \%$, respectively. However, these results were from patients with aortic stenosis who were at intermediate to high surgical risk versus high to prohibitive SAVR surgical risk. When survival rates were further stratified by firstgeneration valve types, Deutsch et a ${ }^{27}$ reported 1,5 , and 7 year estimated survival rates at $76.0 \%, 40.2 \%$, and $23.2 \%$, respectively.

Table 4. TAVR access site by valve type.

\begin{tabular}{|c|c|c|c|c|c|}
\hline \multirow{2}{*}{$\begin{array}{c}\text { TAVR } \\
\text { vascular } \\
\text { access }\end{array}$} & \multicolumn{2}{|c|}{$\begin{array}{l}\text { Balloon } \\
(\mathrm{N}=183)\end{array}$} & \multicolumn{2}{|c|}{$\begin{array}{l}\text { Self-Expanding } \\
\qquad(\mathrm{N}=86)\end{array}$} & \multirow[b]{2}{*}{$P$ value } \\
\hline & $\mathrm{N}$ & $\%$ & $\mathrm{~N}$ & $\%$ & \\
\hline \multicolumn{6}{|l|}{ Transfemoral } \\
\hline Left & 58 & 31.7 & 25 & 29.1 & \\
\hline Right & 107 & 58.5 & 56 & 65.1 & 0.595 \\
\hline Others* & 18 & 9.8 & 5 & 5.8 & \\
\hline
\end{tabular}


Table 5. Survival estimates by post-operative time points.

\begin{tabular}{|c|c|c|c|c|c|c|}
\hline \multirow[b]{2}{*}{ Month } & \multicolumn{3}{|c|}{ Balloon $(\mathrm{N}=183)$} & \multicolumn{3}{|c|}{ Self-Expanding $(\mathrm{N}=86)$} \\
\hline & Deaths (n) & Still Alive (n) & $\begin{array}{l}\text { Survival Estimate } \\
(\%)[95 \% \mathrm{Cl}]\end{array}$ & Deaths (n) & Still Alive (n) & $\begin{array}{l}\text { Survival Estimate } \\
(\%)[95 \% \mathrm{Cl}]\end{array}$ \\
\hline Index event & 0 & 183 & $100.0[100,100]$ & 1 & 85 & $98.8[92.0,99.8]$ \\
\hline 1 & 3 & 180 & $98.4[95.0,99.5]$ & 3 & 83 & $96.5[89.5,98.9]$ \\
\hline 12 & 24 & 138 & $86.7[80.8,90.9]$ & 13 & 62 & $84.4[74.6,90.7]$ \\
\hline 24 & 36 & 75 & $77.7[70.3,83.5]$ & 19 & 31 & $73.0[60.3,82.2]$ \\
\hline 36 & 46 & 26 & $62.0[50.3,71.7]$ & 23 & 14 & $60.7[44.9,73.2]$ \\
\hline
\end{tabular}

$\mathrm{Cl}=$ Confidence Interval

In contrast to the longer-term survival outcomes post-TAVR studies, there are many previous studies that have reported 30-day mortality and 1-year mortality. ${ }^{8,27-33}$ Kodali et $\mathrm{al}^{34}$ reported a 30 -day mortality of $2.2 \%$ for high risk inoperable TAVR patients receiving an Edwards Sapien $3 \mathrm{BEV}$. In the United States registry-based Sapien 3 observational study for intermediate risk patients by Thourani et al, ${ }^{35}$ the 30 -day and 1-year mortality listed were $1.1 \%$ and $7.4 \%$, respectively. When comparing SEV versus BEV, Rogers et $\mathrm{al}^{33}$ observed a comparable 30-day mortality rate for third generation SEV $(1.4 \%)$ and BEV (1.6\%). In the CoreValve Evolut R CE Study from Australia and the United Kingdom, 30-day and 1 year mortality were $0.0 \%$ and $6.7 \%$, respectively. ${ }^{36}$

Though our results are comparable to other studies for 30-day mortality, our results deviated from the published literature at 1 -year post-TAVR. In our study, patients who received BEV TAVR had 30-day and 1-year mortality rates of $1.6 \%$ and $13.3 \%$, respectively; whereas, patients who received SEV had 30 -day and 1-year mortality rates of $3.5 \%$ and $15.6 \%$, respectively. Our study comprised every patient, including palliative dying patients, in a rural area who received TAVR within our health system, which may have prolonged their lives beyond the 30-day period yet not have improved survival beyond one year. We suspect our patient population was sicker than most other patients enrolled in previously reported studies. However, our results show lower mortality than those reported by Abdel-Wahab et $\mathrm{al}^{8,9,15}$ which may have had even sicker patients than ours. In the CHOICE multicenter trial in Germany, 30-day cardiovascular mortality and 1-year allcause mortality rates were higher in patients with BEV $(4.1 \%$ and $17.4 \%$, respectively) and $\operatorname{SEV}(4.3 \%$ and $12.8 \%$, respectively) than those observed in our study.

In this observational study, which presents a contemporary, real-world example of one rural US-based healthcare system, a multidisciplinary TAVR team determined which patients were at high and prohibitive surgical risk for SAVR based on two independent surgeon evaluations. Thereafter, preoperative work-up for TAVR consisted of computed tomography angiography and transesophageal echocardiogram. Valve selection was determined based on patient aortic valvular anatomy including the annulus size, extent of calcification, and body habitus. The surgeons tended to assign patients with wider annulus preferentially to the BEV group. While this non-random assignment may have created some bias, the surgeon's clinical discretion would matter in the realworld setting of TAVR placement. We adjusted for valve sizes, but this variable was not included in our final model, because it was not predictive. For the covariates we measured, data were evenly distributed between both groups, except that patients with COPD had lower percent predicted FEV1 in the $\mathrm{BEV}$ group.

Unlike a similar observation study to ours, where performance of third-generation valves for symptomatic severe aortic stenosis was compared, we did not find evidence of selection bias of SEVs being primarily allotted to women by the TAVR team. ${ }^{33}$ There were more women who received SEV in our study, but this variation was not statistically significant between groups.

Our center used only the BEV TAVR until later in 2014, when SEVs were used as well. This caused an imbalance in the number of patients assigned to BEV compared with SEV. This difference may be due in part to enrollment criteria for TAVR procedures performed during preliminary clinical trials. Prior to the US Food and Drug administration approval of these TAVR devices, most implanting centers were restricted to one TAVR device during enrollment in the landmark trials. Our center offered SEV to more patients from 2015 onward, which may have influenced our results. We theorize there is a steep learning curve with each device, which may account for the lack of survival advantage seen in our main results. As TAVR devices may be similar in procedural deployment, we thought there may be a transferred learning from the use of $\mathrm{BEV}$ to SEV when they were introduced; however, our results do not conclusively support a survival advantage of BEV.

When we restricted our data to the time period of 2015 to 2017, we found that the BEV performed better in terms of survival. This advantage may be due to prior experience with this device in our center. This will need to be confirmed in subsequent studies. Although this result contradicts our $a$ priori hypothesis, survival may be associated with less need of perioperative pacemaker requirement and lower rates of 
paravalvular leak post-TAVR. ${ }^{33,34,37}$ If we accounted for a similar experiential learning with the SEV in our analysis, we would not have adequate power to assess the head-to-head comparison, but this could be a future research question to address in further studies.

\section{Limitations and Strengths}

Our study was a retrospective analysis of our experience as a tertiary level referral center in rural Midwestern United States and may not reflect experience in other regions of the world. Since patients were not randomized to a valve group based on established clinical criteria but were adjudicated based on the experience of the surgeons and cardiologists in the TAVR team, surgeon preference and comfort level with a particular valve type may have played a considerable role in patient selection to each group. However, covariates in each patientvalve subgroup appeared to have been evenly distributed, unlike a similar observational study reported by Rogers et al. ${ }^{33}$ This may have occurred randomly, and there may be limitations in our analysis from unmeasured confounding, for example frailty. We attempted to do a matched propensity analysis to reduce unmeasured confounding, but we were limited by small numbers.

We obtained information from patient clinical charts and reported echocardiograms instead of direct laboratory analysis. Unfortunately, we could not capture in our database the aortic valve calcium burden and distribution by computed tomography; however, these characteristics were used by the TAVR teams to decide which valve type a patient received. To date, there are no published guidelines on how valvular anatomy influences device choice. ${ }^{33}$

As we only collected data on inoperable high and prohibitive surgical TAVR patients who received different iterations of each valve type, variations in valve model may have introduced heterogeneity in our study and may account for slightly higher mortality rates, although, it is also possible this variation may be obliterating any survival differences between valve types if present. This is supported by findings from the recently published French nationwide study that compared Edwards Sapien 3 to EVOLUT R that showed better survival with the balloon expandable Edward Sapien 3 TAVR recipients compared to EVOLUT R self-expandable TAVR valve type. ${ }^{16}$ In addition, most of our patients were Caucasian, which may limit generalizability of our results to other specific patient populations and races. Although we had no loss to follow-up during our study period, study participants were followed for variable periods of time, which may also introduce survival bias, but, we noted no differences in follow-up times by patient in each valve group. In this study, we report all-cause mortality as our outcome. We attempted to collect information from death certificates to report cardiovascular mortality, but we were limited by small numbers for meaningful comparisons between valve types.

\section{Conclusions}

Although our study findings are limited to a single health system, they represent a real-world observational experience by a TAVR team in a large tertiary center with excellent longterm patient survival with results comparable to outcomes observed in large multicenter studies. Our sub-analysis indicates a possible survival advantage of BEV, which will need to be confirmed in a larger long term study; yet overall, patient survival does not appear to be significantly different between SEV and BEV TAVR devices in patients who cannot undergo SAVR.

\section{Acknowledgments}

The authors acknowledge all the members of the MAVE and TAVR teams at the Marshfield Clinic Health System for their contribution to this work, and Dr. Emily Andreae, PhD, for manuscript editing.

\section{References}

1. Jansen F, Werner N. Interventional treatment of the aortic valve: Current evidence. Herz. 2017;42(6):548-553

2. Tsai MT, Tang GH, Cohen GN. Year in review: transcatheter aortic valve replacement. Curr Opin Cardiol. 2016 Mar;31(2):139-47.

3. Bleiziffer S, Bosmans J, Brecker S, et al. Insights on mid-term TAVR performance: 3-year clinical and echocardiographic results from the CoreValve ADVANCE study [published correction appears in Clin Res Cardiol. 2017 Jul 4;:]. Clin Res Cardiol. 2017;106(10):784-795.

4. Arora S, Ramm CJ, Misenheimer JA, Vavalle JP. TAVR in Intermediate-Risk Patients: A Review of the PARTNER 2 Trial and its Future Implications. J Heart Valve Dis. 2016;25(6):653-656.

5. Rogers T, Torguson R, Bastian R, Corso P, Waksman R. Feasibility of transcatheter aortic valve replacement in low-risk patients with symptomatic severe aortic stenosis: Rationale and design of the Low Risk TAVR (LRT) study. Am Heart J. 2017;189:103-109.

6. Hamm CW, Arsalan M, Mack MJ. The future of transcatheter aortic valve implantation. Eur Heart J. 2016;37(10):803-810.

7. Leon MB, Smith CR, Mack MJ, et al. Transcatheter or Surgical Aortic-Valve Replacement in Intermediate-Risk Patients. N Engl J Med. 2016;374(17):1609-1620.

8. Abdel-Wahab M, Mehilli J, Frerker C, et al. Comparison of balloon-expandable vs self-expandable valves in patients undergoing transcatheter aortic valve replacement: the CHOICE randomized clinical trial. JAMA. 2014;311(15):1503-1514. 
9. Abdel-Wahab M, Neumann FJ, Mehilli J, et al. 1-Year Outcomes After Transcatheter Aortic Valve Replacement With Balloon-Expandable Versus Self-Expandable Valves: Results From the CHOICE Randomized Clinical Trial. J Am Coll Cardiol. 2015;66(7):791-800.

10. Pascale P, Regamey J, Iglesias JF, et al. Cardiologie [Article in French] [Cardiology update in 2015]. Rev Med Suisse. 2016;12(500):17-22.

11. Kar S, Sharma R. Sapien 3: A Triple Threat to Aortic Stenosis. JACC Cardiovasc Interv. 2015;8(14):18171818. doi:10.1016/j.jcin.2015.11.002

12. Wong SC, Pawar S, Minutello RM, et al. Device success and 30-day clinical outcome in patients undergoing preimplant valvuloplasty in transfemoral versus omitting valvuloplasty in transapical transcatheter aortic valve replacement. J Thorac Cardiovasc Surg. 2015;150(5):1111-1117.

13. Hira RS, Vemulapalli S, Li Z, et al. Trends and Outcomes of Off-label Use of Transcatheter Aortic Valve Replacement: Insights From the NCDR STS/ACC TVT Registry. JAMA Cardiol. 2017;2(8):846-854.

14. Chakos A, Wilson-Smith A, Arora S, et al. Long term outcomes of transcatheter aortic valve implantation (TAVI): a systematic review of 5-year survival and beyond. Ann Cardiothorac Surg. 2017;6(5):432-443.

15. Abdel-Wahab M, Landt M, Neumann FJ, et al. 5-Year Outcomes After TAVR With Balloon-Expandable Versus Self-Expanding Valves: Results From the CHOICE Randomized Clinical Trial. JACC Cardiovasc Interv. 2020;13(9):1071-1082.

16. Deharo P, Bisson A, Herbert J, et al. Impact of Sapien 3 Balloon-Expandable Versus Evolut R Self-Expandable Transcatheter Aortic Valve Implantation in Patients With Aortic Stenosis: Data From a Nationwide Analysis. Circulation. 2020;141(4):260-268.

17. Lanz J, Kim WK, Walther T, et al. Safety and efficacy of a self-expanding versus a balloonexpandable bioprosthesis for transcatheter aortic valve replacement in patients with symptomatic severe aortic stenosis: a randomised non-inferiority trial. Lancet. 2019;394(10209):1619-1628.

18. Kappetein AP, Head SJ, Généreux P, et al. Updated standardized endpoint definitions for transcatheter aortic valve implantation: the Valve Academic Research Consortium-2 consensus document (VARC-2). Eur J Cardiothorac Surg. 2012;42(5):S45-S60.

19. Leon MB, Piazza N, Nikolsky E, et al. Standardized endpoint definitions for transcatheter aortic valve implantation clinical trials: a consensus report from the Valve Academic Research Consortium. Eur Heart J. 2011;32(2):205-217.
20. Kappetein AP, Head SJ, Généreux P, et al. Updated standardized endpoint definitions for transcatheter aortic valve implantation: the Valve Academic Research Consortium-2 consensus document (VARC-2). Eur J Cardiothorac Surg. 2012;42(5):S45-S60.

21. Kappetein AP, Head SJ, Généreux P, et al. Updated standardized endpoint definitions for transcatheter aortic valve implantation: the Valve Academic Research Consortium-2 consensus document. Eur Heart J. 2012;33(19):2403-2418.

22. Kappetein AP, Head SJ, Généreux P, et al. Updated standardized endpoint definitions for transcatheter aortic valve implantation: the Valve Academic Research Consortium-2 consensus document. EuroIntervention. 2012;8(7):782-795.

23. Leon MB, Piazza N, Nikolsky E, et al. Standardized endpoint definitions for Transcatheter Aortic Valve Implantation clinical trials: a consensus report from the Valve Academic Research Consortium. J Am Coll Cardiol. 2011;57(3):253-269.

24. Deeb GM, Reardon MJ, Chetcuti S, et al. 3-Year Outcomes in High-Risk Patients Who Underwent Surgical or Transcatheter Aortic Valve Replacement. J Am Coll Cardiol. 2016;67(22):2565-2574.

25. Kapadia SR, Leon MB, Makkar RR, et al. 5-year outcomes of transcatheter aortic valve replacement compared with standard treatment for patients with inoperable aortic stenosis (PARTNER 1): a randomised controlled trial. Lancet. 2015;385(9986):2485-2491.

26. Martin GP, Sperrin M, Hulme W, et al. Relative Survival After Transcatheter Aortic Valve Implantation: How Do Patients Undergoing Transcatheter Aortic Valve Implantation Fare Relative to the General Population? J Am Heart Assoc. 2017;6(10):e007229.

27. Deutsch MA, Erlebach M, Burri M, et al. Beyond the five-year horizon: long-term outcome of high-risk and inoperable patients undergoing TAVR with first-generation devices. EuroIntervention. 2018;14(1):41-49.

28. Brennan JM, Thomas L, Cohen DJ, et al. Transcatheter Versus Surgical Aortic Valve Replacement: PropensityMatched Comparison. J Am Coll Cardiol. 2017;70(4):439450.

29. Yoon SH, Lefèvre T, Ahn JM, et al. Transcatheter Aortic Valve Replacement With Early- and New-Generation Devices in Bicuspid Aortic Valve Stenosis. J Am Coll Cardiol. 2016;68(11):1195-1205.

30. Hebeler KR, Baumgarten H, Squiers JJ, et al. Albumin Is Predictive of 1-Year Mortality After Transcatheter Aortic Valve Replacement. Ann Thorac Surg. 2018;106(5):13021307.

31. Navarese EP, Andreotti F, Ko?odziejczak M, et al. AgeRelated 2-Year Mortality After Transcatheter Aortic Valve Replacement: the YOUNG TAVR Registry. Mayo Clin Proc. 2019;94(8):1457-1466. 
32. Spargias K, Toutouzas K, Chrissoheris M, et al. The Athens TAVR Registry of newer generation transfemoral aortic valves: 30-day outcomes [published correction appears in Hellenic J Cardiol. 2013 Mar-Apr;54(2):152. Stathogianni, Konstantinos [corrected to Stathogiannis, Konstantinos]]. Hellenic J Cardiol. 2013;54(1):18-24.

33. Rogers T, Steinvil A, Buchanan K, et al. Contemporary transcatheter aortic valve replacement with third-generation balloon-expandable versus selfexpanding devices. J Interv Cardiol. 2017;30(4):356361.

34. Kodali S, Pibarot P, Douglas PS, et al. Paravalvular regurgitation after transcatheter aortic valve replacement with the Edwards sapien valve in the PARTNER trial: characterizing patients and impact on outcomes. Eur Heart J. 2015;36(7):449-456.

35. Thourani VH, Kodali S, Makkar RR, et al. Transcatheter aortic valve replacement versus surgical valve replacement in intermediate-risk patients: a propensity score analysis. Lancet. 2016;387(10034):2218-2225.

36. Manoharan G, Walton A, Brecker S, Pasupati S, Blackman DJ, Meredith IT. TCT-98 Clinical Outcomes at 1 Year with a Repositionable Self-Expanding Transcatheter Aortic Valve. Abstract presented at: Twenty-Seventh Annual Symposium Transcatheter Cardiovascular Therapeutics (TCT)-Abstracts (TCT2015); October 13, 2015; New York, NY. In: J Am Coll Cardiol. 2015;66(15)(Suppl):B45-B46. Available at: https://doi.org/10.1016/j.jacc.2015.08.143 . Last accessed: February 23, 2021.

37. De Carlo M, Giannini C, Fiorina C, et al. Paravalvular leak after CoreValve implantation in the Italian Registry: predictors and impact on clinical outcome. Int J Cardiol. 2013;168(5):5088-5089.

\section{Author Affiliations}

Peter E. Umukoro MD, MPH, ScD*a; Paul Yeung-Lai-Wah MD*; Sunil Pathak MD*; Sabri Elkhidir MD*; Deepa Soodi MD*; Brooke Delgoffe MS广; Richard Berg MS广; Kelley P. Anderson MDf; Romel J. Garcia-Montilla MD, MEd, PhD, $\mathrm{MSc} \oint$

*Department of Internal Medicine, Marshfield Clinic Health System, Marshfield, WI USA

†Office of Research Computing and Analytics, Marshfield Clinic Research Institute, Marshfield, WI USA

tDepartment of Cardiology, Marshfield Clinic Health System, Marshfield, WI USA

$\S$ Department of Surgical Intensive Care Unit, Marshfield

Medical Center, Marshfield, WI USA

${ }^{a}$ Current affiliation: Physician, Indiana University School of

Medicine, Indianapolis, IN, USA
Institution where this work was completed: Marshfield Medical Center, Marshfield, Wisconsin.

Scientific Contribution Statement: The principal investigators designed the study. All investigators collected and abstracted data. Data cleaning and analysis were done by project analyst and statistician. All investigators reviewed the data, and all authors approved the final draft of this manuscript for publication. 